\title{
The salting coefficient and size of alkylamines in saline media at different temperatures: estimation from Pitzer equations and the mean spherical approximation
}

\author{
C Taboada-Pan, I Brandariz, J.L Barriada, T Vilariño, M.E Sastre de Vicente' \\ Facultade de Ciencias, Departamento de Química Física e Enxeñería Química I, \\ Universidade da Coruña 15071, La Coruña, Spain
}

Fluid Phase Equilibria

Volume 180, Issues 1-2, 15 April 2001, Pages 313-325

Received 27 September 2000, Accepted 23 January 2001, Available online 7 May 2001

doi:10.1016/S0378-3812(01)00358-2

\begin{abstract}
The renewed theoretical interest in the proton transfer associated to the amino group together with the scarcity of acid-base studies of amines in moderate to concentrated saline media focussed our attention on the study of the basicities of some alkylamines, namely monomethyl, dimethyl and trimethylamine, in aqueous saline solutions of $\mathrm{KCl}$ at various temperatures.

A non-conventional analysis of stoichiometric equilibrium constants versus ionic strength data is carried out. On one hand, Pitzer's model is easily applied to calculate the salting coefficient and the thermodynamic equilibrium constant of the alkylamines. On the other hand, the mean spherical approximation has the advantage over the Debye-Hückel based theories that it can account for effects produced by species of different sizes. Here, it is applied to predict the dependence of the salting behavior on the size of the alkylamines.
\end{abstract}

\section{Keywords}

Pitzer model; Mean spherical approximation; Chemical equilibrium; Activity coefficients; Salting coefficient; Size of alkylamines 


\section{Introduction}

The equilibrium constant for the ionization of simple amines

$$
\mathrm{R}_{3} \mathrm{NH}^{+} \rightarrow \mathrm{R}_{3} \mathrm{~N}+\mathrm{H}^{+}
$$

can be formulated as

$$
K^{\mathrm{T}}=\frac{\left[\mathrm{R}_{3} \mathrm{~N}\right]\left[\mathrm{H}^{+}\right]}{\left[\mathrm{R}_{3} \mathrm{NH}^{+}\right]} \frac{\gamma_{\mathrm{R}_{3} \mathrm{~N}} \gamma_{\mathrm{H}}+}{\gamma_{\mathrm{R}_{3} \mathrm{NH}}+}=K^{*} \frac{\gamma_{\mathrm{R}_{3} \mathrm{~N}} \gamma_{\mathrm{H}}+}{\gamma_{\mathrm{R}_{3} \mathrm{NH}}+}
$$

where $K^{\mathrm{T}}$ represents the thermodynamic equilibrium constant, $K^{*}$ the stoichiometric equilibrium constant and $\gamma_{i}$ the activity coefficient of each species. Taking natural logarithms one obtains

$$
\mathrm{p} K^{*}=\mathrm{p} K^{\mathrm{T}}+\log \gamma_{\mathrm{R}_{3} \mathrm{~N}}+\log \gamma_{\mathrm{H}}+-\log \gamma_{\mathrm{R}_{3} \mathrm{NH}}+
$$

It is well known that amines together with carboxylic and phenolic groups play a very important role in chemistry as functional groups and their thermodynamics of protonation has been extensively studied in aqueous solution. In fact, of all the hundred or so common neutral groups, only the amino groups and certain substituted nitrogens are of sufficient basicity to be protonated within the acidity $\mathrm{pH}$ range of aqueous solutions [1].

Despite of the substantial body of data in the chemical literature, most of them have been obtained in pure water or in dilute saline solutions; as an example, in the classical and detailed paper of Everett and Wynne-Jones [2] about the protonation of methylamines the highest salt concentration is $0.2 \mathrm{M}$. However, there is also practical interest in the chemistry of methylamines in more concentrated saline solutions, like the marine environment where the presence of these compounds has been reported in recent years [3].

On the other hand, the irregular order of the basicity of methylamines in aqueous solutions compared to that in gas phase, mentioned in [1], has often aroused the interest in acidity/basicity studies in solution. As a matter of fact, several theoretical approaches, taking into account the effects of the solvent, have been carried out very recently [4], [5], [6] and [7].

Consequently, bearing in mind, on the one hand, the scarcity of acid-base studies in moderate to concentrated saline media and, on the other hand, the renewed theoretical interest in the proton transfer associated to the amino group, we have undertaken a study of the basicities of methyl, dimethyl and trimethylamine, in aqueous potassium chloride saline solutions in the concentration range of $0.2-1.5 \mathrm{M}$. 
For the calculation of some thermodynamic properties of aqueous electrolyte solutions the Pitzer model is widely used because it has mathematical flexibility and high accuracy. Thus, the salting coefficient together with the thermodynamic equilibrium constant for the studied alkylamines can be easily calculated by use of the Pitzer equations. But Debye-Hückel based theories are not sensitive to ion-size changes and, as a result, the Pitzer model can not be used to predict the dependence of the salting behavior of solutions on ion sizes.

The MSA theory has the advantage over the models based on Debye-Hückel theory that it can account for effects produced by species of different sizes. Thus, MSA formulas are applied to estimate a mean diameter of the amines from the salting coefficients previously calculated.

The application of different treatments to study the acid-base equilibrium in saline media has been the aim of several recent reviews [8], [9] and [10].

\section{Experimental}

Monomethyl, dimethyl and trimethylammonium chlorides - $\left(\mathrm{CH}_{3}\right) \mathrm{H}_{2} \mathrm{NHCl}$, $\left(\mathrm{CH}_{3}\right)_{2} \mathrm{HNHCl},\left(\mathrm{CH}_{3}\right)_{3} \mathrm{NHCl}$, background electrolyte $(\mathrm{KCl})$ and titrants $(\mathrm{KOH}$ and $\mathrm{HCl})$ were Merck p.a.

Titrations were carried out in a dual-wall cell that was kept at a constant temperature by circulating water from a thermostat. Purified nitrogen was bubbled through the solutions in order to ensure thorough homogenization and $\mathrm{CO}_{2}$ removal. Titrants were added from a Crison microBu 2030 autoburette furnished with $2.5 \mathrm{ml}$ syringes, additions were computer-controlled. An electrode connected to a Crison micropH $2000 \mathrm{pH}$-meter, also interfaced to a computer, was used to measure emf values to within $\pm 0.1 \mathrm{mV}$. Due to the high partial pressure of the amines, several bubblers are used [2].

Alkylammonium salts $(0.0100 \mathrm{M})$ were titrated by adding standardized $0.1000 \mathrm{M} \mathrm{KOH}$. An appropriate amount of inert electrolyte $(\mathrm{KCl})$ was added to all solutions in order to maintain a constant ionic strength. Each $\mathrm{p} K$ value is an average of several experiments performed always with two electrodes Radiometer GK2401C. The SUPERQUAD program was used to calculate the constants.

Electrodes were calibrated by adding $\mathrm{HCl}+\mathrm{KCl}$ to a solution of supporting electrolyte, both containing the same chloride ion concentration. Emf versus $\mathrm{p}\left[\mathrm{H}^{+}\right]$plots were fitted to the equation $E=E^{0}-s \mathrm{p}\left[\mathrm{H}^{+}\right]$, in order to calculate the formal potential, $E^{0}$, and the slope of the electrode, $s$, [11]. 


\section{Results and discussion}

Fig. 1 shows a very good linear relationship between $\mathrm{p} K^{*}(I)$ and ionic strength data in the range of $\mathrm{KCl}$ concentrations studied.
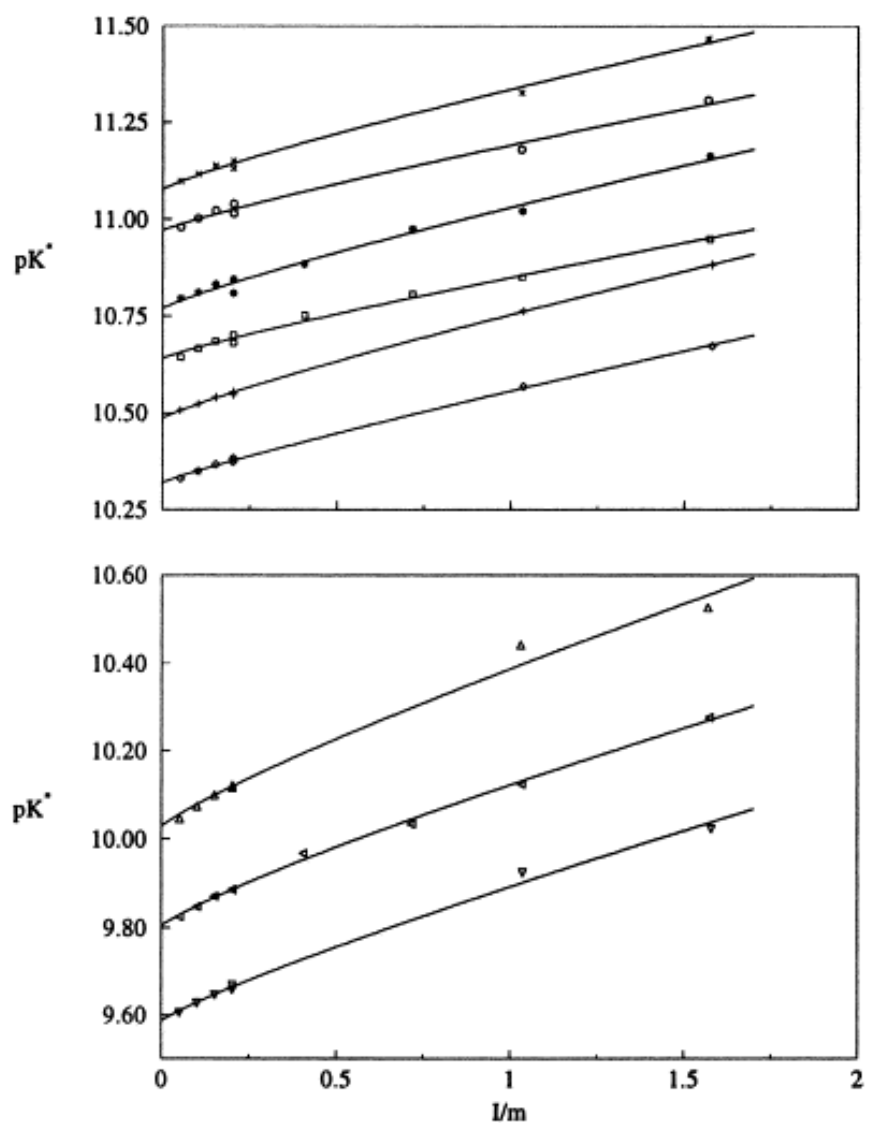

Fig. 1 .

Experimental $\mathrm{p} K^{*}$ data of the alkylamines vs. molality of $\mathrm{KCl}$ at different temperatures: monomethylamine data at $15^{\circ} \mathrm{C}(\mathrm{\circ})$, $25^{\circ} \mathrm{C}(\square), 35^{\circ} \mathrm{C}(\diamond)$; dimethylamine data at $15^{\circ} \mathrm{C}(\times), 25^{\circ} \mathrm{C}(*), 35^{\circ} \mathrm{C}(+)$; trimethylamine data at $15^{\circ} \mathrm{C}(\Delta)$, $25^{\circ} \mathrm{C} \quad(\triangleleft), \quad 35^{\circ} \mathrm{C} \quad(\nabla) . \quad$ Curves correspond to Pitzer model fitting.

At first sight such linear trend could be explained by assuming a mutual compensation of the activity coefficients for species $\mathrm{R}_{3} \mathrm{NH}^{+}$and $\mathrm{H}^{+}$in Eq. (3), which would lead to an expression where the $\mathrm{p} K^{*}$ would depend solely on the activity coefficient of the neutral species.

As a rule, the activity coefficient for a neutral species B in a background electrolytic solution can be approximated, in many cases, by a Setchenow-like equation [12]

$$
\ln \gamma_{\mathrm{B}}=k_{\mathrm{B}} I
$$

where $k_{\mathrm{B}}$ the so-called salting or Stechenow coefficient.

Different theories accounting for salting (in/out) effects have been described in literature [12]. Of different treatments, the classical thermodynamic compression (electrostriction) treatment proposed by Long and McDevitt [13], is simple and gives 
good account of salting out effects. Moreover, the salting coefficient can be easily related to molecular volumes for solute according to the equation

$$
k_{\mathrm{B}}=\frac{\vec{V}_{\mathrm{B}}^{0}\left(V_{\mathrm{s}}-\vec{V}_{\mathrm{s}}^{0}\right)}{2.3 \beta_{0} R T}
$$

where $\bar{V}_{\mathrm{B}}^{0}$ the partial molar volume of the non electrolyte at infinite dilution $\left(1 \mathrm{~mol}^{-1}\right), V_{\mathrm{s}}$ the molar volume of pure liquid electrolyte, $\bar{V}_{\mathrm{s}}^{0}$ the partial molar volume of electrolyte at infinite dilution, and $\beta_{0}$ is the compressibility of pure water. Then, we get for two different molecules in the same background electrolyte

$$
\frac{k_{i}}{k_{j}}=\frac{\overrightarrow{V_{i}}}{\vec{V}_{j}^{0}}
$$

i.e. the ratio of salting coefficients equals to the quotient of partial molar volume of solutes $i$ and $j$ at infinite dilution.

Since it is difficult to suggest a value for the size of the methylamines in solution from the ratio of molar volumes, the mean spherical approximation has been applied to estimate a diameter of each amine. The rationale for this choice rests on the fact that the mean spherical approximation has the advantage over models based on the classical Debye-Hückel equation in that it is sensitive to size variations, which is required for modeling salting behavior [14].

\subsection{Estimate of salting coefficients by means of Pitzer equations}

The activity coefficient of the species in Eq. (2) according to Pitzer equations are as follows [15]

$\ln \gamma_{\mathrm{R}_{3} \mathrm{~N}}=2\left(\lambda_{\mathrm{R}_{\mathrm{N}, \mathrm{Cl}}}+\lambda_{\mathrm{R}_{3} \mathrm{~N}, \mathrm{~K}}\right) I=2 \lambda I, \quad \ln \gamma_{\mathrm{H}^{+}}=f^{\gamma}+2 I B_{\mathrm{BCl}}+B_{\mathrm{KCl}}^{\prime} I^{2}, \quad \ln \gamma_{\mathrm{R}_{3} \mathrm{NH}^{+}}=f^{\gamma}+2 I B_{\mathrm{R}_{3} \mathrm{NH}, \mathrm{Cl}}+B_{\mathrm{KCl}}^{\prime} I^{2}$

where $C^{\varphi}, \psi$ and $\theta$ parameters have been omitted because the ionic strength is not greater than 2 molal[15]. The second virial coefficient " $B$ " may be expressed as a function of the ionic strength and $\beta^{(0)}$ and $\beta^{(1)}$ parameters, in that case Eq. (3) becomes once reorganized,

$\mathrm{p} K^{*}+\left(\beta_{\mathrm{R}_{3} \mathrm{NH}, \mathrm{Cl}}^{(1)}-\beta_{\mathrm{HCl}}^{(1)}\right) \frac{1-(1+2 \sqrt{I}) \exp (-2 \sqrt{I})}{\ln 10}=\mathrm{p} K^{\mathrm{T}}+\left(\lambda-\beta_{\mathrm{R}_{3} \mathrm{NH}, \mathrm{Cl}}^{(0)}+\beta_{\mathrm{HCl}}^{(0)}\right) \frac{2 I}{\ln 10}$ 
The salting coefficient on a molal scale $\lambda$ and the thermodynamic constant for each amine can be easily calculated from Eq. (8) as long as all $\beta$ parameters are known, which can be obtained from activity coefficient data for $\mathrm{HCl}$ and osmotic coefficient data for alkylammonium salts, as it will be explained in next sections.

\subsubsection{Pitzer parameters of alkylammonium salts}

Pitzer interaction parameters between $\mathrm{R}_{3} \mathrm{NH}^{+}$and $\mathrm{Cl}^{-}$can be obtained from osmotic coefficient data for each alkylammonium salt, whose dependence on ionic strength according to the Pitzer model is given by[15]

$$
\phi-1+A_{\phi}\left(\frac{\sqrt{I}}{1+1.2 \sqrt{I}}\right)=\beta_{\mathrm{R}_{3} \mathrm{NH}, \mathrm{Cl}}^{(0)} I+\beta_{\mathrm{R}_{3} \mathrm{NH}, \mathrm{Cl}}^{(1)} I \exp (-2 \sqrt{I})+C_{\mathrm{R}_{3} \mathrm{NH}, \mathrm{Cl}}^{\phi} I^{2}
$$

Data up to 6 molal were taken from the paper of Macaskill and Bates [16]. The parameters obtained are given in Table 1. As can be seen, data were fitted with and without the weighting factor proposed by Pitzer when $I>4 \mathrm{M}$. The difference is so small that it is even less than experimental error.

\section{Table 1.}

Pitzer's parameters of alkylammonium salts at $25^{\circ} \mathrm{C}^{\mathrm{a}}$

\begin{tabular}{|l|l|l|l|l|}
\hline & $\beta^{(0)}$ & $\beta^{(1)}$ & $C^{\varphi}$ & Weight \\
\hline$\left(\mathrm{CH}_{3}\right) \mathrm{H}_{2} \mathrm{NHCl}$ & $0.0562(0.0008)$ & $0.109(0.009)$ & $-0.0031(0.0001)$ & No \\
& $0.0567(0.0008)$ & $0.104(0.009)$ & $-0.0032(0.0001)$ & Yes \\
\hline$\left(\mathrm{CH}_{3}\right)_{2} \mathrm{HNHCl}$ & $0.0566(0.0007)$ & $0.026(0.008)$ & $-0.0021(0.0001)$ & No \\
\hline & $0.0570(0.0008)$ & $0.023(0.008)$ & $-0.0022(0.0001)$ & Yes \\
\hline$\left(\mathrm{CH}_{3}\right)_{3} \mathrm{NHCl}$ & $0.0534(0.0006)$ & $-0.053(0.006)$ & $-0.00049(0.00009)$ & No \\
& $0.0535(0.0006)$ & $-0.054(0.006)$ & $-0.00052(0.00011)$ & Yes \\
\hline
\end{tabular}

a Parameter error is given in brackets.

On the other hand, taking into account that $\mathrm{p} K^{*}(I)$ data were determined at several temperatures, the value of the parameters in Eq. (8) is needed at the aforementioned temperatures. If the temperature derivative, $\left(\partial \beta^{(0)} / \partial T\right)$, of one parameter is known, together with the value of the parameter itself at a certain temperature, $\beta^{(0)}\left(T_{0}\right)$, then the value at any other temperature $T_{1}$, will be given by

$$
\beta_{\mathrm{MX}}^{(0)}\left(T_{1}\right)=\beta_{\mathrm{MX}}^{(0)}\left(T_{0}\right)+\frac{\partial \beta_{\mathrm{MX}}^{(0)}(T)}{\partial T}\left(T_{1}-T_{0}\right)
$$


By use of the parameters calculated at $25^{\circ} \mathrm{C}$ (given in Table 1) and the temperature derivatives evaluated by Pitzer from calorimetric data and listed in [15], $\beta$ values for alkylammonium salts were obtained at 15 and $35^{\circ} \mathrm{C}$, as can be seen in Table 2 .

Table 2.

Pitzer's parameters of alkylammonium salts at 15 and $35^{\circ} \mathrm{C}$

\begin{tabular}{|c|c|c|c|c|c|c|}
\hline & \multicolumn{2}{|c|}{$\left(\mathrm{CH}_{3}\right) \mathrm{H}_{2} \mathrm{NHCl}$} & \multicolumn{2}{|c|}{$\left(\mathrm{CH}_{3}\right)_{2} \mathrm{HNHCl}$} & \multicolumn{2}{|l|}{$\left(\mathrm{CH}_{3}\right)_{3} \mathrm{NHCl}$} \\
\hline & $15^{\circ} \mathrm{C}$ & $35^{\circ} \mathrm{C}$ & $15^{\circ} \mathrm{C}$ & $35^{\circ} \mathrm{C}$ & $15^{\circ} \mathrm{C}$ & $35^{\circ} \mathrm{C}$ \\
\hline$\beta^{(0)}$ & 0.0551 & 0.0573 & 0.0564 & 0.0568 & 0.0532 & 0.0536 \\
\hline$\beta^{(1)}$ & 0.098 & 0.120 & 0.008 & 0.044 & -0.088 & -0.018 \\
\hline$\left[\partial \beta^{(0)} / \partial T\right]_{\mathrm{P}}$ & $1.13 \times 10^{-4}$ & $1.13 \times 10^{-4}$ & $0.23 \times 10^{-4}$ & $0.23 \times 10^{-4}$ & $0.22 \times 10^{-4}$ & $0.22 \times 10^{-4}$ \\
\hline$\left[\partial \beta^{(1)} / \partial T\right]_{\mathrm{P}}$ & $10.8 \times 10^{-4}$ & $10.8 \times 10^{-4}$ & $18.2 \times 10^{-4}$ & $18.2 \times 10^{-4}$ & $35.3 \times 10^{-4}$ & $35.3 \times 10^{-4}$ \\
\hline
\end{tabular}

\subsubsection{Pitzer parameter of $\mathrm{HCl}$}

Activity coefficient data taken from the compilation by Harned and Owen [17] have been used to evaluate Pitzer's parameters of $\mathrm{HCl}$ at different temperatures by means of the following equation:

$$
\ln \gamma_{\mathrm{HCl}}-f^{\gamma}=2 I \beta_{\mathrm{HCl}}^{(0)}+\frac{1}{2}\left(\beta_{\mathrm{HCl}}^{(1)}\right)[1-(1+2 \sqrt{I}-2 I) \exp (-2 \sqrt{I})]+\frac{3}{2} C_{\mathrm{HCl}}^{\phi} I^{2}
$$

where

$$
f^{\gamma}=-A_{\phi}\left[\frac{\sqrt{I}}{1+1.2 \sqrt{I}}+\frac{2}{1.2} \ln (1+1.2 \sqrt{I})\right]
$$

When necessary the value of $A_{\varphi}$ at the working temperatures have been taken from [18]. Another way to find the parameters at 15 and $35^{\circ} \mathrm{C}$ is using Eq. (10), as described previously. The results obtained with both and can be seen in Table 3. Agreement is good in view of the experimental error. $\beta^{(0)}$ and $\beta^{(1)}$ values obtained from Eq. (11) are the parameters used in this work, on the other hand $C^{\varphi}$ is not used to fit $\mathrm{p} K^{*}$ versus $I$, because the ionic strength is less than 2 molal. 
Table 3.

Pitzer's parameters of $\mathrm{HCl}$ at 15,25 and $35^{\circ} \mathrm{C}^{\mathrm{a}}$

\begin{tabular}{|c|c|c|c|c|c|}
\hline$T\left({ }^{\circ} \mathrm{C}\right)$ & $\beta^{(0)}$ & $\beta^{(1)}$ & $C^{\varphi}$ & $I_{\max }$ & Obtained by \\
\hline \multirow[t]{2}{*}{15} & $0.1804(0.0009)$ & $0.286(0.004)$ & $0.0017(0.0002)$ & 4 & Eq. $(11)^{\mathrm{b}}$ \\
\hline & 0.1806 & 0.293 & 0.0002 & 4.5 & Eq. $(10)^{\mathrm{c}}$ \\
\hline \multirow[t]{2}{*}{25} & $0.1761(0.0008)$ & $0.295(0.003)$ & $0.0013(0.0002)$ & 4 & Eq. $(11)^{\mathrm{b}}$ \\
\hline & 0.1775 & 0.295 & 0.0008 & 6 & Taken from [15] \\
\hline \multirow[t]{2}{*}{35} & $0.1734(0.0004)$ & $0.296(0.002)$ & - & 2 & Eq. $(11)^{b}$ \\
\hline & 0.1744 & 0.296 & 0.0014 & 4.5 & Eq. $(10)^{c}$ \\
\hline
\end{tabular}

a Errors are given in brackets.

b Fitting data taken from [17] table 11-4-1A.

c Being: $T_{0}=25\left[\partial \beta^{(0)} / \partial T\right]_{\mathrm{P}}=-3.081 \times 10^{-4}$;

$\left[\partial \beta^{(0)} / \partial T\right]_{\mathrm{P}}=1.419 \times 10^{-4} ;[\partial C \varphi / \partial T]_{\mathrm{P}}=-6.213 \times 10^{-5}[15]$.

\subsubsection{Salting coefficient of the amines}

Stoichiometric equilibrium constants for mono-, di- and trimethylamine at various temperatures and ionic strengths of $\mathrm{KCl}$, are listed in Table 4. Data with an asterik has been interpolated at 15,25 and $35^{\circ} \mathrm{C}$ by means of a cubic spline with data from Everett and Wynne-Jones'work [2]. The remaining data were obtained with the glass electrode as described in the experimental section.

Table 4.

Experimental $\mathrm{p} K^{*}$ data of methylamine (MMA), dimethylamine (DMA) and trimethylamine (TMA) as a function of molality of $\mathrm{KCl}$, at different temperatures

\begin{tabular}{|r|r|r|r|r|r|r|r|r|r|}
\hline$I(\mathrm{~m})$ & \multicolumn{3}{|c}{$T=15^{\circ} \mathrm{C}$} & \multicolumn{3}{c}{$T=25^{\circ} \mathrm{C}$} & \multicolumn{3}{c|}{$T=35^{\circ} \mathrm{C}$} \\
& MMA & DMA & TMA & MMA & DMA & TMA & MMA & DMA & TMA \\
\hline $0.05^{\mathrm{a}}$ & 10.979 & 11.097 & 10.046 & 10.644 & 10.795 & 9.824 & 10.330 & 10.507 & 9.605 \\
\hline $0.10^{\mathrm{a}}$ & 11.001 & 11.114 & 10.073 & 10.666 & 10.812 & 9.847 & 10.348 & 10.522 & 9.626 \\
\hline $0.15^{\mathrm{a}}$ & 11.022 & 11.137 & 10.099 & 10.684 & 10.832 & 9.870 & 10.367 & 10.541 & 9.646 \\
\hline $0.20^{\mathrm{a}}$ & 11.038 & 11.149 & 10.115 & 10.701 & 10.845 & 9.886 & 10.383 & 10.554 & 9.657 \\
\hline
\end{tabular}




\begin{tabular}{|l|l|l|l|l|l|l|l|l|l|l|}
\hline 0.20 & 11.014 & 11.130 & 10.121 & 10.680 & 10.809 & 9.886 & 10.373 & 10.547 & 9.669 \\
\hline 0.41 & - & - & - & 10.752 & 10.884 & 9.967 & - & - & - \\
\hline 0.72 & - & - & - & 10.807 & 10.974 & 10.034 & - & - & - \\
\hline 1.03 & 11.179 & 11.327 & 10.441 & 10.850 & 11.021 & 10.124 & 10.567 & 10.764 & 9.923 \\
\hline 1.57 & 11.309 & 11.468 & 10.526 & 10.948 & 11.163 & 10.276 & 10.673 & 10.883 & 10.024 \\
\hline
\end{tabular}

a Data taken from [2].

At 0.20 molal $\mathrm{p} K_{s}^{*}$ determined with both, hydrogen and glass electrodes are available. Agreement is rather good, since the difference arise in the second or even in the third figure of the $\mathrm{p} K$ value.

Provided that interaction parameters for $\mathrm{HCl}$ and $\mathrm{R}_{3} \mathrm{NHCl}$ are known (Table 1, Table 2 and Table 3), $\mathrm{p} K^{\mathrm{T}}$ and $\lambda$ can be obtained by application of the Pitzer model, Eq. (8), to the data given in Table 4. The values obtained are shown in Table 5, which also includes the slope calculated from the linear fit of $\mathrm{p} K^{*}$ versus $I$ (molal).

Table 5 .

Values of the thermodynamic $\mathrm{p} K$ and the salting coefficient in molal, $\gamma$, and molar scale, $k B$, obtained for monomethylamine, dimethylamine and trimethylamine at the temperatures studied ${ }^{\text {a }}$

\begin{tabular}{|l|l|l|l|l|l|}
\hline & $T\left({ }^{\circ} \mathrm{C}\right)$ & $\mathrm{p} K^{\mathrm{T}}$ & $\lambda$ & $k B$ & Slope (molal scale) \\
\hline$\left(\mathrm{CH}_{3}\right) \mathrm{H}_{2} \mathrm{NH}$ & 15 & $10.972(0.007)$ & $0.072(0.011)$ & $0.090(0.011)$ & $0.205(0.009)$ \\
\hline & 25 & $10.642(0.005)$ & $0.065(0.008)$ & $0.083(0.008)$ & $0.194(0.009)$ \\
\hline & 35 & $10.320(0.003)$ & $0.103(0.004)$ & $0.124(0.004)$ & $0.222(0.006)$ \\
\hline$\left(\mathrm{CH}_{3}\right)_{2} \mathrm{HNH}$ & 15 & $11.078(0.006)$ & $0.092(0.009)$ & $0.111(0.010)$ & $0.237(0.006)$ \\
\hline & 25 & $10.771(0.007)$ & $0.099(0.011)$ & $0.119(0.012)$ & $0.239(0.009)$ \\
\hline & 35 & $10.487(0.002)$ & $0.115(0.003)$ & $0.137(0.003)$ & $0.246(0.004)$ \\
\hline & 15 & $10.030(0.012)$ & $0.173(0.019)$ & $0.196(0.020)$ & $0.327(0.022)$ \\
\hline & 25 & $9.806(0.004)$ & $0.139(0.006)$ & $0.160(0.007)$ & $0.290(0.008)$ \\
\hline & 35 & $9.587(0.006)$ & $0.138(0.010)$ & $0.160(0.010)$ & $0.279(0.012)$ \\
\hline
\end{tabular}

a The slope from the linear fitting of $\mathrm{p} K^{*}$ vs. molality is also given. Errors are given in brackets. 
Experimental data are plotted together with Pitzer curves in Fig. 1.

\subsection{Lewis-Randall (LR) to McMillan-Mayer (MM) conversion}

In contrast to Pitzer equations, which use experimental data on a molality scale (LR theory), MSA expresses thermodynamic quantities in terms of the McMillan-Mayer (MM) theory of solutions. Thus, data obtained by Pitzer model have to be converted into molarity data (MM theory) [19] and [20].

On the basis of the results obtained in previous studies [21], [22] and [23], we simplified corrections to the conversion of molal to molar scale, neglecting the osmotic pressure effects. Any given molality can be changed to the molar concentration according to the equation

$$
C=\frac{m d(t)}{1+0.001 M m}
$$

where $m$ the molality of the salt, $M$ its molar mass and $d(t)$ the density of the solution at temperature $t$, which can be calculated by the equation

$$
d(t)=d_{0}(t)+\left(a_{1}+b_{1} t+c_{1} t^{2}\right) C-\left(a_{2}+b_{2} t+c_{2} t^{2}\right) C^{3 / 2}
$$

where $d_{0}(t)$ represents the density of the pure solvent at temperature $t$

$$
d_{0}(t)=a_{0}+b_{0} t-c_{0} t^{3 / 2}
$$

For a given electrolyte, all parameters of and are constants which are found tabulated [24].

The experimental activity coefficient data were converted into molarity scale according to

$$
\ln \gamma_{\mathrm{MM}}=\ln \gamma_{\mathrm{LR}}+\ln \left(\frac{d_{0}}{d}(1+0.001 \mathrm{Mm})\right)
$$

where $\gamma_{\mathrm{MM}}$ and $\gamma_{\mathrm{LR}}$ are the activity coefficients in molar and molal scale, respectively.

Salting coefficients on molar and molal scales are evaluated from a linear plot of $\ln \gamma_{\mathrm{MM}}$ versus $C$ and $\ln \gamma_{\mathrm{LR}}$ versus $m$. The results are given in Table 5 .

\subsection{Estimate of the sizes of amines by means of MSA}

Once salting coefficients are known, MSA formulas are applied to estimate a mean diameter. Any property in the framework of MSA for the primitive model of ionic solutions [25], [26], [27], [28] and [29] is the sum of the excess thermodynamic property, named electrostatic contribution, and the hard-sphere contribution, which

takes into account the excluded volume of the particles [21], [22], [27], [28], [29] and [30]. 
Assuming that there is no electrostatic contribution to the activity coefficient of neutral molecules, their activity coefficient is equal to the hard-sphere contribution. The expression of which for the case that there are two or more particles of differing size, regardless of their charge, is evaluated from the Percus-Yevick equation [28]

$\ln \gamma_{i}^{\mathrm{hs}}=-\ln \left(1-X_{3}\right)+\frac{\sigma_{\mathrm{B}}^{3} X_{0}+3 \sigma_{\mathrm{B}}^{2} X_{1}+3 \sigma_{\mathrm{B}} X_{2}}{1-X_{3}}+\frac{3 \sigma_{\mathrm{B}}^{3} X_{1} X_{2}+9 / 2 \sigma_{\mathrm{B}}^{2} X_{2}^{2}}{\left(1-X_{3}\right)^{2}}+\frac{3 \sigma_{\mathrm{B}}^{3} X_{2}^{3}}{\left(1-X_{3}\right)^{3}}$

where

$$
X_{k}=\frac{\pi}{6} \sum_{i} \rho_{i} \sigma_{i}^{k}, \quad k=0,1,2,3
$$

with $\rho_{i}$ the number density of the species $\left(\rho i=N_{\mathrm{A}} C i\right.$, where $C_{i}$ is the concentration of each species and $N_{\mathrm{A}}$ the Avogadro constant), $\sigma_{\mathrm{B}}$ represents the average diameter of the neutral organic molecule and $\sigma_{i}$ refers to all species making up the hard spheres mixture.

The activity coefficient for the neutral amines modelized by MSA Eq. (16) can be approximated to be equal to the Setchenow-like Eq. (4) where the value of the salting coefficient has been previously calculated by means of Pitzer equations. The rationale for this choice rests on the fact that the hard-sphere term was analyzed in a previous work [31] and found to be roughly proportional to the ionic strength of the solution.

The MSA calculations have been performed using a hard core diameter of the electrolyte and a relative permittivity of the solvent, both concentration-dependent, as proposed by Simonin and Blum [23].

3.3.1. Hard-sphere diameter of the electrolyte and relative permittivity of the solvent

Calculations of variation of the hard core size and relative permittivity with the concentration have been performed following the procedure proposed by Simonin and Blum [23], who found that both density dependent parameters could be fitted by a simple linear law

$$
\begin{aligned}
& \sigma(C)=\sigma^{(0)}+\sigma^{(1)} \frac{C}{C_{0}} \\
& \varepsilon(C)=\varepsilon^{(0)}+\varepsilon^{(1)} \frac{C}{C_{0}}
\end{aligned}
$$

where $C_{0}=1 \mathrm{~mol} \mathrm{dm}^{-3}$ 
The above mentioned authors determined these parameters at $25^{\circ} \mathrm{C}$. Using the available experimental data [32] and following the same procedure, the deviation between experimental and calculated mean activity coefficient has been minimized in this work to obtain the same parameters at 15 and $35^{\circ} \mathrm{C}$.

If we look for a mean ionic diameter, denoted by $\sigma$, then expressions for both electrostatic and hard-sphere contribution to the activity coefficient of a 1:1 electrolyte are given by the so-called restricted MSA model[27], [28], [33] and [34]

$$
\begin{gathered}
\ln \gamma_{ \pm}^{\mathrm{el}}=\frac{\alpha^{2} \Gamma}{4 \pi(1+\Gamma \sigma)} \\
\ln \gamma_{ \pm}^{\mathrm{hs}}=-\ln (1-X)+\frac{7 X}{1-X}+\frac{15 X^{2}}{2(1-X)^{2}}+\frac{3 X^{3}}{(1-X)^{3}}
\end{gathered}
$$

where

$$
\begin{gathered}
\alpha^{2}=\frac{4 \pi e^{2}}{\varepsilon_{0} \varepsilon k T} \\
\Gamma=\frac{(1+2 \kappa \sigma)^{1 / 2}-1}{2 \sigma} \\
\kappa=\left[\alpha^{2} \sum_{i=1}^{n} \rho_{i} z_{i}^{2}\right]^{1 / 2}=\left[\alpha^{2} \rho\right]^{1 / 2} \\
X=\frac{\pi}{3} \rho \sigma^{3} \\
\rho=\sum \rho_{i}
\end{gathered}
$$

where $\sigma$ the mean electrolytic diameter and $\varepsilon$ the relative permittivity of the solution, both concentration-dependent according to and, $\varepsilon_{0}$ the permittivity of vacuum, which is a function of the temperature, $k_{\mathrm{B}}$ the Boltzmann constant and $T$ the temperature. 
After conversion to molar scale, experimental mean activity coefficient data for $\mathrm{KCl}$ at different temperatures were fitted by use of the restricted MSA model, varying the permittivity for the solvent and the mean diameter of electrolyte. The results obtained are summarized in Table 6 . The range over which a successful fit between calculated and experimental data was obtained is also given.

Table 6.

Concentration-dependent parameters obtained for the hard core diameter of $\mathrm{KCl}$ and relative permittivity of the solvent from MSA calculations at different temperatures ${ }^{\mathrm{a}}$

\begin{tabular}{|l|l|l|l|}
\hline \multicolumn{5}{|l|}{$T\left({ }^{\circ} \mathrm{C}\right)$} \\
& 15 & 25 & 35 \\
\hline$\sigma^{(0)}(\AA)$ & 3.1647 & 3.0332 & 3.088 \\
\hline $10^{3} \sigma^{(1)}(\AA)$ & 4.713 & -3.732 & -12.686 \\
\hline$\varepsilon^{(0)}$ & 84.28 & 81.62 & 79.62 \\
\hline$\varepsilon^{(1)}$ & -5.591 & -2.964 & -3.284 \\
\hline$C_{\max }\left(\mathrm{mol} \mathrm{dm}^{-3}\right)$ & 3.68 & 4.16 & 3.65 \\
\hline
\end{tabular}

a The highest concentration which gives a successful fit is also given.

\subsubsection{Size of the amines}

According to Eq. (16), the hard-sphere activity coefficient of the neutral molecule of each amine was estimated by means of MSA on the basis of previously calculated parameters. The value of the average hard core diameter of each amine was adjusted until the best fit between the MSA hard-sphere term and salting coefficient on molar scale was found, according to the equation [35], [36] and [37]

$$
\ln \gamma^{\text {hs }}=k_{\mathrm{B}} C
$$

Table 7 shows the diameters obtained by applying the MSA model to data. As can be seen, the experimental data of the amines are described by different effective average diameter of the neutral species at each temperature but they do not differ markely. 
Table 7.

Mean diameters $(\AA)$ of the alkylamines obtained by use of MSA in $\mathrm{KCl}$ at different temperatures and compared with those diameters found in literature at $25^{\circ} \mathrm{C}$

\begin{tabular}{|l|l|l|l|}
\hline & $\left(\mathrm{CH}_{3}\right) \mathrm{H}_{2} \mathrm{NH}$ & $\left(\mathrm{CH}_{3}\right)_{2} \mathrm{HNH}$ & $\left(\mathrm{CH}_{3}\right)_{3} \mathrm{NH}$ \\
\hline MSA & & & \\
\hline$T=15^{\circ} \mathrm{C}$ & 3.57 & 4.02 & 5.52 \\
\hline$T=35^{\circ} \mathrm{C}$ & 4.43 & 4.68 & 5.08 \\
\hline$T=25^{\circ} \mathrm{C}$ & 3.55 & 4.37 & 5.12 \\
\hline Bondi [38] & 4.26 & 4.82 & 5.24 \\
\hline Schroeder [39] & 5.38 & 6.06 & 6.6 \\
\hline Le bas [39] & 5.18 & 5.98 & 6.58 \\
\hline RISM-SCM [6] & 6.2 & 6.3 & 6.5 \\
\hline Cabani [40] & 5.12 & 5.76 & 6.18 \\
\hline
\end{tabular}

The diameters obtained by means of MSA at $25^{\circ} \mathrm{C}$ have been compared to those calculated from molar volumes proposed by several authors [6], [38], [39] and [40] and taking the neutral molecules as spheres. Data of Table 7 show that Bondi's diameters are the closest values to those obtained from MSA calculations.

\section{Conclusions}

The linear Setchenow-type dependence on ionic strength is a relatively common behavior for protonation of amines in dilute to moderate saline solutions. Such linearity has been reported, within the accuracy of data even up to 5 molal in ionic strength [41]. Nevertheless, the salting coefficient of the alkylamines estimated from the slope of the linear $\mathrm{p} K-I$ plots differs considerably from the values calculated by use of the Pitzer equations, which indicates the low level of confidence of assuming the cancelation of the activities coefficients for the species charged of Eq. (3), Table 5.

The MSA has the advantage over models based on the classical Debye-Hückel model that it can account for effects produced by size variations, which is a requirement for modeling salting behavior. The approximation in the framework of MSA that there is no 
electrostatic contribution to the activity coefficient of the neutral molecules leads to molecular sizes which appears to be rather realistic.

A remarkable fact of our results is that Bondi's radii lead to the better fit of the experimental data by use of MSA. So, it can be stated that radii proposed by Bondi are a good choice for MSA calculations and could be used to evaluate salting coefficients.

\section{List of symbols}

$\mathrm{A} \varphi \quad$ Debye-Hückel constant for the osmotic coefficient

$B \quad$ second virial coefficient

C molar concentration

$C^{\varphi} \quad$ third virial coefficient

$D \quad$ density of solution

I ionic strength

$k \quad$ salting coefficient in molar scale

$\mathrm{K} \quad$ equilibrium constant

$m$ molal concentration

$M \quad$ molar mass

$N_{\mathrm{A}} \quad$ Avogadro constant

$R \quad$ universal gas constant

$t \quad$ temperature

$T \quad$ absolute temperature

$\bar{V}$ partial molar volume

$V \quad$ molar volume

\section{Greek symbols}

$\beta_{0} \quad$ compressibility of pure water

$\beta^{(0)}, \beta^{(1)}$ second virial coefficients for double interactions between ions of different charge signs

$\varepsilon \quad$ permittivity constant

$\gamma \quad$ activity coefficient

$\lambda \quad$ second virial coefficient for neutral species (salting coefficient in molal scale)

$\rho \quad$ number density of particles

$\sigma \quad$ diameter

$\varphi \quad$ osmotic coefficient

$\psi \quad$ third virial coefficient for mixing effects

\section{Superscripts}

$\begin{array}{ll}\text { el } & \text { electrostatic } \\ \text { hs } & \text { hard-spheres }\end{array}$




$$
\begin{array}{ll}
\mathrm{T} & \text { thermodynamic } \\
* & \text { stoichiometric } \\
0 & \text { pure species }
\end{array}
$$

\section{Subscripts}

$\begin{array}{ll}\mathrm{B} & \text { non electrolytic species } \\ i, j, k & \text { solvent species } \\ \mathrm{LR} & \text { Lewis-Randall } \\ \mathrm{MM} & \text { McMillan-Mayer } \\ \mathrm{S} & \text { electrolytic species }\end{array}$

\section{Acknowledgements}

MESV thanks Xunta de Galicia for financial support received in the framework of Project XUGA 10310B97.

\section{References}

1. F.M. Jones, E.M. Arnett

Prog. Phys. Org. Chem., 11 (1977), p. 263

2. D.H. Everett, W.F.K. Wynne-Jones

Proc. Roy. Soc. London Ser., 177A (1941), p. 499

3. M.F. Fitzsimons, A.W. Jemmett, G.A. Wolff

Org. Geochem., 27 (1997), p. 15

4. J.L. Pascual-Ahuir, J. Andrés, E. Silla

Chem. Phys. Lett., 169 (1990), p. 297

5. J. Tuñón, E. Silla

J Tomasi

J. Phys. Chem., 96 (1992), p. 9043

6. M. Kawata, S. Ten-no, S. Kato, F. Hirata

J. Am. Chem. Soc., 117 (1995), p. 1638

7. M. Kawata, S. Ten-no, S. Kato, F. Hirata Chem. Phys., 203 (1996), p. 53

8. M.E. Sastre de Vicente

Curr. Top. Solution Chem., 2 (1997), p. 253

9. P.G. Daniele, C. De Stefano, C. Foti, S. Sammartano

Curr. Top. Solution Chem., 2 (1997), p. 157 
10. M.E. Sastre de Vicente, T. Vilariño, I. Brandariz Recent Res. Devel. Phys. Chem., 2 (1998), p. 489

11. S. Fiol, F. Arce, X.L. Armesto, F.J. Penedo, M. Sastre de Vicente Fresenius J. Anal. Chem., 343 (1992), p. 469

12. B.E. Conway Pure Appl. Chem., 57 (1985), p. 263

13. F.A. Long, W.F. McDevitt Chem. Rev., 51 (1951), p. 119

14. R.S. Wu, L. Lee Fluid Phase Equilibr., 78 (1992), p. 1

15. K.S. Pitzer, Activity Coefficients in Electrolyte Solutions, 2nd Edition, CRC Press, Boca Raton, 1991.

16. J.B. Macaskill, R.G. Bates J. Solution Chem., 15 (1986), p. 323

17. H.S. Harned, B.B. Owen, The Physical Chemistry of Electrolytic Solutions, 3rd Edition, Reinhold, New York, 1958.

18. D.G. Archer, P. Wang J. Phys. Chem. Ref. Data, 19 (1990), p. 371

19. H.L. Friedman, J. Solution Chem. 1 (1972) 387, 413 and 419.

20. J.P. Simonin

J. Chem. Soc., Faraday Trans., 92 (1996), p. 3519

21. R. Triolo, J.R. Grigera, L. Blum J. Phys. Chem., 80 (1976), p. 1858

22. R. Triolo, L. Blum, M.A. Floriano J. Phys. Chem., 82 (1978), p. 1368

23. J.P. Simonin, L. Blum

J. Chem. Soc., Faraday Trans., 92 (1996), p. 1533

24. O. Söhnel, P. Novotný, Densities of Aqueous Solutions of Inorganic Substances, Physical Sciences Data 22, Elsevier, Amsterdam, 1985.

25. E. Waisman, J.L. Lebotwitz

J. Chem. Phys., 56 (1972), p. 3086

26. L. Blum

Mol. Phys., 30 (1975), p. 1529

27. L. Blum, J.S. Høye

J. Phys. Chem., 81 (1977), p. 1311 
28. J.M.G.M. Barthel, H. Krienke, W. Kunz, Physical Chemistry of Electrolyte Solutions. Modern Aspects, Topics in Physical Chemistry 5, Deutsche Bunsen-Gesellschaft für Physiktalische Chemie, Steinkopff, Darmstadt, Springer, New York, 1998.

29. C. Sanchez-Castro, L. Blum

J. Phys. Chem., 93 (1989), p. 7478

30. P. Turq, J. Barthel, M. Chemla, Transport, relaxation and kinetic processes in electrolyte solutions, Lectures Notes in Chemistry 57, Springer, Berlin, 1992.

31. T. Vilariño, M.E. Sastre de Vicente

J. Phys. Chem., 100 (1996), p. 16378

32. I.D. Zaytez, G.G. Aseyev (Eds.), Properties of Aqueous Solutions of Electrolytes. Translated by M.A. Lazarev and V.R. Sorochenko, CRC Press, Boca Raton, FL, 1992.

33. H.L. Friedman, Pair correlation function theory. in: A Course in Statistical Mechanics, Prentice-Hall, Englewood Cliffs, NJ, 1985.

34. W.R. Fawcett, A.C. Tikanen

J. Phys. Chem., 100 (1996), p. 4251

35. T. Vilariño, I. Brandariz, S. Fiol, X.L. Armesto, M.E. Sastre de Vicente

J. Chem. Soc., Faraday Trans., 93 (1997), p. 413

36. T. Vilariño, M.E. Sastre de Vicente

Phys. Chem. Chem. Phys., 1 (1999), p. 2453

37. A.C. Tikanen, W.R. Fawcett

J. Electroanal. Chem., 439 (1997), p. 107

38. A. Bondi

J. Phys. Chem., 68 (1964), p. 441

39. R.C. Reid, J.M. Prausnitz, B.E. Poling, The Properties of Gases and Liquids, 4th Edition, Chemical Engineering Series, McGraw-Hill International Editions, Singapore, 1988.

40. S. Cabani, P. Gianni, V. Mollica, L. Lepori

J. Solution Chem., 10 (1981), p. 563

41. D.A. Palmer, D. Wesoliwski

J. Solution Chem., 16 (1987), p. 571

Corresponding author. Fax: +34-981-167-065 